\title{
Entrepreneurship Teaching Design Based On Case Study
}

\author{
Fang Fang \\ Network Engineering and Research Center, \\ South China Univ. of Technology, \\ Guangzhou, China, 510641 \\ ffang@scut.edu.cn
}

\author{
Luo Xinge* \\ Network Engineering and Research Center, \\ South China Univ. of Technology, \\ Guangzhou, China, 510641 \\ xluo@scut.edu.cn
}

\begin{abstract}
This paper proposes an entrepreneurial teaching design based on case study. Entrepreneurship helps students develop entrepreneurial thinking by teaching business and financial skills, behaviors and attitudes to complement the IT skills acquired in network engineering courses. By simulating the opening of an Internet book bar, this paper shows the details of processes, such as collecting customer needs, evaluating environment, analyzing costs, and drawing conclusions. By completing a case study, students can use the skills they have learned to solve problems and develop business plans for potential businesses. The teaching design contains interactive activities to make the teaching process more active.
\end{abstract}

Keywords-Entrepreneurship; Case study; Teaching design; Business plan

\section{INTRODUCTION}

The goal of cultivating university entrepreneurial talents is to have a broad knowledge base and entrepreneurial knowledge in a professional field. Specifically, it focuses on developing students' eight abilities: decision-making ability; ability to respond; ability to build team culture; innovation ability; negotiation ability; communication ability; organizational ability, and financing ability. [1]

Universities should offer a variety of entrepreneurship courses. Entrepreneurial ability is an important indicator for evaluating the quality of talent training. Students of all majors can take an entrepreneurship education course, complete a business research report, and submit a business plan.

\section{ENTREPRENEURIAL THINKING}

\section{A. Recognize a problem}

Ming is a student, he hopes to have a comfortable environment near the university, access to the Internet, chat, and reading, but he found that there is no suitable place nearby. When he realizes that his problem has no readily available solution, he considers starting a new business to solve the problem. This is entrepreneurial thinking. Entrepreneurs create, operate, and assume the risk for a new business venture. $\mathrm{He}$ recognizes that a problem can be a business opportunity.

\section{B. Identify possible solutions}

Entrepreneurs have more control over their time, have the opportunity to create wealth, and can create a working environment they like. At the same time, there will be entrepreneurial risks, such as: business may fail; have long hours of hard work; may have financial insecurity and so on. Therefore, it is necessary to reduce the risk of starting a business. Newcomers to entrepreneurship need to find an experienced person to be an advisor; have a well-thought-out plan; be prepared to be sometimes discouraged and exhausted; do somethings that they know. [2]

One of the most powerful ways to minimize the risk of starting a new business is to use a teacher or an advisor. Advisors use their own experience to help the newcomers solve problems, weigh risks and stay excited about the business. Ming asks his teacher Mr. Zhang to be his advisor.

Mr. Zhang prompts Ming to describe what a "perfect" solution to his problem would look like. Ming makes a list of the important characteristics that he thinks the solution should provide. Important characteristics are the features that will have the greatest impact on customer satisfaction. These features are the ones that need to be present in whatever new business idea Ming choose to implement. Identifying options is the first step in the decision-making process.

Classroom interactive activities: Students need to consider what types of new business opportunities can provide most or all of the features that they described in their "perfect" solution.

\section{Refer to the following example:}

The perfect solution: Reliable and fast Internet access; convenient hours; quiet and comfortable; reasonably priced; no need wait; easy to get to; no need to bring own computer; network printer...

\section{Evaluate possible solutions}

Business ideas must pass a validity test to determine if they are real business opportunities. An idea might be a good business opportunity under the following conditions:

- $\quad$ Other people need the product to solve a problem they have. 
- The entrepreneur has the skills to create the business.

- The product can be supplied at a price that people are willing to pay while the business owners to make a profit.

- $\quad$ The business is sustainable.

- The technology exists to create the business. [2]

\section{ENTREPRENEURIAL PLANNING}

\section{A. Business research}

Ming decides to open an Internet book bar. Ming seeks advice from his teacher who tells him that he needs to research.

The business environment surrounds the company and impacts the decision-making process.

The complete business environment is made up of three distinct environments:

- Macro-environment - Factors that can impact the business but are out of the control of the entrepreneur. This includes legal, political, economic, technological, and cultural environments.

- Micro-environment - Factors that the entrepreneur has some influence over but does not control. This includes customers, suppliers, and competitors.

- Internal environment - Factors that the entrepreneur has total control over. This includes employees, materials, equipment, time, and the company's money. [2]

Resources for business research includes: Internet research; Magazine articles; Library; Surveys; Personal interviews; Statistical research; Industry research and so on.

Competitors are businesses that sell similar products. An entrepreneur must research who their competitors are, who the competitor's customers are, how the competitor prices the product and which additional products the competitor offers.

Classroom interactive activities: Students need to research the competitors to gather information about the businesses, the products, and the customers.

Refer to the following example: Internet Coffee Shop in the city center

- Customers are young

- Professionals age 20-40 and students.

- Almost everyone is eating or drinking coffee or juice.

- Supplies sold: memory sticks, discs, notebooks...

- They charge RMB10 for 1 hour of computer time.

- The customers have to wait a long time-only one computer station.

- They offer wireless.

- Customers complained there is no printer.
Because Ming is still a university student, he plans to invite his friends to work together. They will share responsibilities equally and want to keep their business as simple to operate as possible. It makes sense to structure their business as a partnership.

\section{B. Business evaluation}

After the market research, they make conclusions:

- They will be the employees of the Internet book bar. They can work after school and on the weekends.

- Customers' ages match the age of the customers around the university.

- They should consider having more computers.

- They should provide network printers and wireless networks.

- They should consider selling snacks and drinks.

- They will open with used equipment.

- They will collect a lot of interesting books donated by university teachers and classmates. These books are free for customers to read.

\section{ENTREPRENEURIAL DECIDING}

\section{A. The Products}

The Internet book bar is an example of a business that could offer both products and services. It will offer Internet access, which is a service, and snacks and drinks which are products.

Ming and his friends identified possible products, evaluated the research and decided to sell Internet connectivity using computers and wireless network, a networked printer, book reading corner, and snacks and drinks provided by a delivery service. They have three choices: a coffee bar, a delivery service, or vending machines. The delivery service provided the best quality product using the fewest resources.

Classroom interactive activities: Students need to discuss which choice is the best.

\section{B. Business location}

Choosing the right location is an important part of ensuring the success of a business. There are several factors to consider when choosing a location: Cost; Accessibility; Competitors; Special business needs.

Classroom interactive activities: Students need to discuss what conditions are best for the location

Eventually Ming and his friends chose a location on a busy street and bus line. It's near the university and office buildings. Two ISP providers cover this area. 


\section{Promotion}

Ming and his friends need to promote their new business. The goal of promotion is to establish a positive image of the business through advertising and publicity.

The rule for choosing a promotional tool is to reach the most potential customers at the least cost. Ming and his friends choose to use flyers. Flyers reach the target market at a reasonable cost. They will promote the book bar by printing flyers and handing them out at the university and office building near the Internet book bar.

\section{Cost analysis}

Mr. Zhang reminds Ming, that the Internet book bar is a new business; they will have both start-up costs and operating costs.

Start-up costs are those where money is spent before any sales are made. Start-up costs can include license and permits, legal advice, promotional materials, initial supplies, furniture, and equipment. Operating costs are recurring costs that are necessary to operate the business. These can include utilities (Water, electricity and communication), insurance, wages, and rent. Operating costs consist of fixed and variable costs. Fixed costs do not change if sales go up or down. Rent is an example of a fixed cost. Variable costs change if sales go up or down. Supplies are an example of a variable cost. If more customers use the printer, more paper and ink are needed. [2]

Classroom interactive activities: Each group students lists the related cost and estimates the money Ming will pay out. Refer to the following example:

- Start-up costs: License; Permit; Sales counter; Computers; Desks and chairs; Wires and cables; Router; Printer; Flyers...

- Monthly operating costs: Utilities; Insurance; ISP provider; Supplies; Cakes; Coffee...

\section{E. Earns income}

A business earns income by selling products. Income is the money paid to a business by its customers. For a business to continue operating, income must be greater than or equal to costs. When income exceeds costs the company makes a profit. Profit is the money remaining after costs are paid from the income. The selling price of one unit of the product the business sells. The selling price is the amount the customer pays for the product. To be profitable, the price must be high enough to pay the costs but low enough to attract customers. A successful entrepreneur finds the balance between quality and price that will give the customer the value they seek. [2]

Ming and his friends will sell one hour of Internet connectivity. The retail side of the book bar will offer one product at a time, for example, one cake, one cup of coffee or juices. Ming's research shows that the competition is charging RMB10 for 1 hour of connection time. They also meet the competition's product choices by offering snacks and drinks and have a competitive advantage by offering print services and free book reading.
Ming and his friends have completed their path to entrepreneurship and are ready to open their Internet book bar. Mr. Zhang recommends that Ming and his friends compile all the research they have done and the decisions they have made into one document called a business plan.

\section{WRITING THE BUSINESS PLAN}

A business plan is a document that explains a business opportunity and how it will be carried out. It provides the longterm goals for a company and the ways to reach them. A good business plan discusses the obstacles a business might face and how the company plans to overcome those obstacles. The primary reason to write a business plan is to organize the operating ideas and decisions before the business opens. A well-written plan guides the entrepreneurs every step of the way as they develop a new business. Business plans contain the following information:

- Executive Summary - Reviews the highlights from each section of the business plan.

- Business Description - Describes what the business is, why the business exists, and what customer needs is served by the business.

- Market Analysis- Include the macro, micro and internal environments.

- Management - Lists the qualifications of the people who will operate the company, including the advisors.

- Financials - Shows the estimated profitability of the company. [2]

\section{A. Business Description}

The Internet book bar offers affordable internet access. It is conveniently located near the University. Customers can access the Internet, watch movies, play games, read books, or be a place for friends to meet.

\section{- Company Ownership}

Internet book bar will be a partnership owned and operated by Ming and his friends.

\section{- The Company Story}

The Internet book bar was formed from the owners' need to have fast, convenient, reliable access to the Internet. They discovered that other people in their university also hoped to have a comfortable environment, accessing to the Internet, chatting, and reading.

\section{- $\quad$ The Products}

The Internet book bar leases a line from the ISP provider. One hour of connection time will be sold for RMB10.00. The Internet book bar will have a competitive advantage by selling print services. The price for each printed page is RMB0.1. Snacks and drinks for the book bar will be provided by a delivery service. The price for these goods will be the cost plus ten percent. 


\section{B. Market Analysis}

- Industry:

The number of Internet cafes operating has increased in the last few years. Customers continue to seek a relaxed environment to access the internet and socialize. The industry is becoming more competitive as other businesses begin to sell Internet services.

The Internet book bar will meet the competitive challenge by maintaining a high quality of service, having knowledgeable employees, and offering their products at a price that is affordable.

- The Internet book bar will target:

Younger people and students who seek a place to use the Internet and meet with friends. Young professionals access a wide range of information.

The owners will promote the bar by distributing flyers to the target market. Initially the flyers will be handed-out at the university and office building near the book bar location.

\section{- Competition:}

The Internet book bar will have the advantage of being the first Internet cafe near the university. Competition will come from the coffee shop in the city center.

The Internet book bar will establish a competitive advantage over the coffee shop by providing multiple workstations, wireless network, reducing or even eliminating the wait times, and a lot of free books. The Internet book bar will achieve a further advantage by offering a networked print service.

\section{- Pricing Strategy:}

Internet book bar pricing will be comparable to the competition, but with the value-added feature of immediate convenience.

\section{Management}

The Management section shows that the management team can effectively manage the business. It includes:

- Background information of the entrepreneurs

- Responsibilities of each team member

- List of advisors

Management Team: Internet book bar is owned and operated by Ming and his friends. They are guided by their teacher (a professor of Business College).

Classroom interactive activities : Students discuss the division of tasks in the team, such as: responsible for network equipment, sales and cost control.

\section{Financial}

The Financial Section of the business plan proves that the business can operate at a profit. It includes an estimated income statement. The income statement shows the company's revenue, cost, and profits for a defined period of time. For existing businesses, this section includes actual performance data for the past 3 to 5 years. For new companies this section deals is projections.

\section{E. Executive Summary}

The Executive Summary is one of the most important parts of a business plan. It summarizes the important points that are detailed in the other sections of the business plan. It is the last section to be written but it should be placed as the first section in the business plan.

Classroom interactive activities : Students discuss the executive summary. It will emphasize key issues and includes the following items:

- Company profile

- Target market

- Background of the management team

- $\quad$ Sales and profit projections

\section{CONCLUSION}

This case study introduces entrepreneurial thinking and decision-making process. After completing this case study, students will be able to: Identify and research a business opportunity; explain the decision making process; Practice the decision making process; prepare a simplified business plan. Even if students decide not to become an entrepreneur, this course can help them develop employee skills that are useful in any job.

Universities should foster entrepreneurial culture, encourage adventure, be patient, and be willing to cooperate. Through the entrepreneurship education curriculum, we hope to create a strong entrepreneurial atmosphere, cultivate students' entrepreneurial awareness, entrepreneurial ability, and make the entrepreneurial spirit penetrate into the entire teaching process [3].

\section{REFERENCES}

[1] Zhu chunkui, Li wenjuan, Gong chen, Yang tianbo, The Experience and Enlightenment of Building an Entrepreneurial University in Stanford University, Science and technology of China, 2018(6), pp28-30. (In Chinese).

[2] https://www.cisco.com/, 2018

[3] Wu jijun, The Enlightenment of American Entrepreneurial University to the Development of Chinese Colleges and Universities Industrial\&Science Tribune, 2018(17)3, pp13-14. (In Chinese). 